\title{
ADAPTIVE DENSITY DEPENDENCE OF AVIAN CLUTCH SIZE
}

\author{
ChristiaAn Both, ${ }^{1,3}$ Joost M. Tinbergen, ${ }^{2}$ and Marcel E. Visser ${ }^{1}$ \\ ${ }^{1}$ Netherlands Institute of Ecology, P.O. Box 40, 6666 ZG Heteren, The Netherlands \\ ${ }^{2}$ University of Groningen, Zoological Laboratory, P.O. Box 14, 9750 AA Haren, The Netherlands
}

\begin{abstract}
In birds, the annual mean clutch size is often negatively correlated with population density. This relationship is at least in part due to adjustment by individuals. We investigated whether this response is adaptive in two ways. First we used an optimality model to predict how optimal clutch size (the clutch size that maximizes the number of breeding birds [recruits and surviving parents] in the next season) varies with density. We parameterized the model using data on fitness consequences of experimental variation in brood size and natural variation in population density in a Great Tit (Parus major) population. Predicted optimal clutch size decreased with density, but the predicted relationship was stronger than the observed relationship. Second, we investigated the relationship between the annual selection differential for clutch size and density. We found no relationship, indicating that there is no selection for a steeper than observed relationship between clutch size and density. This implies that the observed response is adaptive, and that the prediction of the optimality model lacks some important constraints or selection pressures. We further used the optimality model to examine the sensitivity of the optimal clutch size to density at different stages in the reproductive cycle. This analysis suggested that the nestling stage was most important. To the best of our knowledge this is the first study that makes quantitative predictions of optimal clutch size in relation to population density.
\end{abstract}

Key words: adaptation, clutch size; brood size manipulation; clutch size; density dependence; fitness; optimality model; Parus major; reaction norm.

\section{INTRODUCTION}

Explanations for the variation in the number of offspring produced by individuals are of interest to both population ecologists and life history theorists. Where life history theory puts emphasis on the selection pressures shaping the observed patterns, population ecology emphasizes the consequences of the observed patterns for the regulation of numbers. In this paper we use an optimality approach to study density-dependent reproduction, and argue that both approaches can and should be integrated to reach a full understanding of the phenomenon of density dependence.

Life history theory outlines how reproductive patterns can be studied in an evolutionary context. With regard to clutch size it predicts that individuals should lay on average the number of eggs that maximizes their fitness (Lack 1947, Drent and Daan 1980, Lessells 1991, Stearns 1992). Empirical estimates of fitness consequences of alternative clutch sizes have been obtained by experimentally reducing and enlarging broods, to control for individual variation in resource availability (Perrins and Moss 1975, van Noordwijk and de Jong 1986). Some of these studies have shown that the natural clutch size indeed maximized fitness, since both reduced and enlarged clutches had lower

Manuscript received 28 June 1999; revised 17 November 1999; accepted 28 November 1999; final version received 24 December 1999.

${ }^{3}$ Present address: University of Groningen, Zoological Laboratory, P.O. Box 14, 9750 AA Haren, The Netherlands. fitness than the unmanipulated clutches (e.g., Perrins and Moss 1975, Högstedt 1980, Nur 1986, Gustafsson and Sutherland 1988, Pettifor et al. 1988, Cooch et al. 1989, Daan et al. 1990, Tinbergen and Daan 1990, Pettifor 1993a, b). Others failed to show this (e.g., Lessells 1986, Finke et al. 1987, Verhulst 1995, Both et al. 1998, Tinbergen and Both 1999). Thus, the observed clutch size is often optimized to local circumstances, but not always so.

Studies of clutch size optimization, however, did not address the question of which environmental conditions clutch size was adjusted to meet. To date most empirical work on clutch size optimization implicitly assumes a constant environment (but see Daan et al. 1990). Organisms, however, can respond to variation in environmental conditions and these adjustments have been called reaction norms (Stearns and Koella 1986). To test whether reaction norms are adaptive, fitness consequences of reproductive decisions need to be quantified in relation to the environmental conditions.

Adaptive responses to environmental conditions depend on prevailing selection pressures. The mechanism underlying selection is often competition for resources, and the strength of selection is therefore related to the number of competitors. By measuring selection during different periods in the life cycle, one determines when competition plays an important role and for which resources competition occurs (reviewed by Sinclair 1989, Newton 1998). The consequence of competition is density-dependent reproduction and/or mortality (Nichol- 


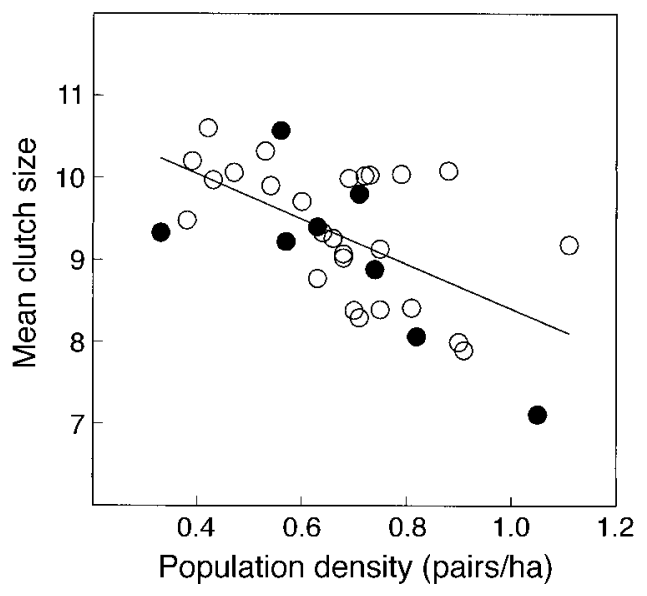

FIG. 1. Annual mean clutch size and density for the Great Tit population on the Hoge Veluwe (1961-1994). Open circles $=$ nonexperimental years; solid circles $=$ experimental years (regression analysis on all years: $F_{1,32}=16.7, P<0.001$ ).

son 1933, Lack 1954), and here the fields of life history theory and population ecology meet: the effect of intraspecific competition on reproductive decisions at an individual level translates to density-dependent reproduction at the level of the population.

The life history approach is to measure selection pressures and build optimization models that predict the optimal response to environmental variation which, in case of genetic variation for the trait, may lead to selection. The technique is to construct one measure of fitness that integrates lifetime effects of competition, which is of prime importance to scale effects of competition that take place in different episodes of the life cycle. Furthermore, the extent of competition during different episodes is not independent. Reproduction might be adjusted to future levels of competition, and hence affects the extent of competition that is measured in each period. Population ecology benefits from these optimization models because they can predict how changes in selection pressures will change optimal reaction norms and subsequent important demographic parameters (Sutherland 1996a). These two approaches are strongly interrelated, and both views are needed to reach a better understanding of how density dependence works.

This paper focuses on the reaction norm of clutch size on population density in Great Tits (Parus major), and specifically addresses the question whether the observed negative reaction norm of annual mean clutch size on population density is adaptive (Fig. 1). Experiments have shown that density causally affects clutch size and other reproductive parameters (Kluyver 1951, Dhondt et al. 1992, Both 1998b), and density-dependent clutch size is a behavioral response of individual females adjusting their clutch size to changes in density (Both 1998a). In this species it has been suggested that clutch size is adjusted to the amount of food during egg-laying (Perrins 1970, Källander 1974), the number of nestlings parents can feed (Lack 1947, van Balen 1973), or to the selection on fledging mass set by the amount of competition juveniles face after fledging (Krebs and Perrins 1978). Furthermore, clutch size of the first brood has been shown to affect the probability to produce a second brood. Clutch size therefore is a compromise between the expected fitness of the first and second broods (Tinbergen 1987, Tinbergen and Daan 1990, Verhulst 1995). Clutch size decisions thus might be the result of selection pressures acting at different periods during the life cycle.

We will address the question whether the observed reaction norm of clutch size to density is optimal by calculating the optimal clutch size at different population densities and determining whether it decreases with density. We estimate the parameters for the equations in the model from experimental data by statistical analysis of eight years of brood size manipulations. The predicted optimal clutch size response is compared with data on the correlation between annual mean clutch size and population density in the same population for 30 years in which no brood size experiments were performed. Although clutch size may be optimized at the individual level (e.g., Perrins and Moss 1975, Pettifor et al. 1988, Tinbergen and Daan 1990; but see Both et al. 1998, Tinbergen and Both 1999), we focus on how the annual mean clutch of the population is related to density, because we do not have data on how local density at the individual level affects individual clutch size decisions and their fitness consequences.

The role of density on the different stages of the reproductive cycle is investigated by separating the effect of density on fitness components corresponding to the period before fledging, after fledging, and the residual parental fitness. This gives an indication of which period in the season clutch size is primarily adjusted to, and hence whether density dependence of clutch size is a response to immediate or future competition.

If model and data differ in the strength of the densitydependent relationship, this can either be due to nonadaptive reaction norms or to the model not including all important selection pressures and/or constraints. In the former case we expect a correlation between selection for clutch size and population density in the data. Therefore we calculated selection differentials for clutch size at different population densities and used them as an independent test of the optimization model.

\section{Methods}

\section{The optimality model}

The optimal clutch size is calculated by using an optimality model. The currency we use is the number of genes of a single parent in the breeding population of the next year, and is calculated as half the number 
of recruits by the parent (from all broods in a season) plus the survival probability of the parent to the next year. This fitness measure does not include any costs of reproduction on parental fecundity in future years, nor the effects of chick growth conditions on their reproductive success. Although some evidence exists of these effects (Gustafsson and Sutherland 1988, Haywood and Perrins 1992, Visser and Verboven 1999), they were not found in this population of Great Tits (Tinbergen and Daan 1990). The variable to be optimized in the model is the clutch size of the first brood $\left(C_{1}\right)$ (Eq. 1). We are concerned with the effects of $C_{1}$ and density $(D)$ on each of the fitness components:

$$
\begin{aligned}
\operatorname{Fitness}\left(C_{1}, D\right)= & 0.5 \times\left[f_{1}\left(C_{1}, D\right)+f_{2}\left(C_{1}, D\right)\right] \\
& +S_{\mathrm{P}}\left(C_{1}, D\right)
\end{aligned}
$$

where $f_{1}$ is the value of the first brood, $f_{2}$ is the value of the second brood, and $S_{\mathrm{P}}$ is the parental survival to the next year, and fitness is measured as the number of genes a single parent contributes to the next year's population. The value of the first brood is

$$
f_{1}\left(C_{1}, D\right)=C_{1} \times f_{\mathrm{N}}\left(C_{1}, D\right) \times f_{\mathrm{R}}\left(M\left[C_{1}, D\right], D\right)
$$

where $f_{\mathrm{N}}$ is nestling survival and $f_{\mathrm{R}}$ the recruitment rate of fledglings. In the calculations $f_{\mathrm{R}}$ was based on two separate functions: fledging mass $(M)$ as a function of clutch size and density, and recruitment rate as a function of fledging mass and density. Recruitment rate is thereby dependent on both the clutch size and the density. The value of second broods is

$$
\begin{aligned}
f_{2}\left(C_{1}, D\right)= & p_{2}\left(C_{1}, D\right) \times C_{2}(D) \times f_{\mathrm{N}}\left(C_{2}, D\right) \\
& \times f_{\mathrm{R}}\left(M\left[C_{2}, D\right], D\right)
\end{aligned}
$$

where $C_{2}$ is the clutch size of the second brood. The probability of producing a successful second brood $\left(p_{2}\right)$ is affected by the clutch size of the first brood, as this probability declined with increasing experimental brood size (Tinbergen 1987, Tinbergen and Daan 1990). The other factors determining the value of the second brood were assumed to be dependent only on the size of the second clutch (see Tinbergen and Daan 1990).

The clutch size giving the maximum value of fitness $\left(C_{1}, D\right)$ under different densities was found numerically.

\section{Brood size experiments}

The equations in the optimality model outlined above are parameterized using brood size manipulations in order to calculate the optimal clutch sizes. In the rest of the paper we refer to brood size when effects of experimental brood size on fitness measures are considered. Although the model is based on experimental variation in brood size and not on variation in clutch size, we refer to the outcomes of the model as optimal clutch size. For simplicity we assume that all eggs in a clutch hatch, and thus that manipulating brood size just after hatching of the eggs is a good model for examining fitness consequences of alternative clutch size decisions.

Experimental protocol.-We reanalyze brood size manipulations in Great Tits already presented by Tinbergen and Daan (1990) with three additional years of data. These manipulations were carried out from 1983 to 1990 on the Hoge Veluwe area in the Netherlands. Three clutches of the same size and hatching on the same date were selected. Within these triplets, one was reduced by approximately half of the young, one was increased by the same number of chicks, and one served as a control. To control for possible quality differences between broods, some of the chicks were swapped between the three broods in a triplet. Brood size manipulations were carried out on day $1-3$ (where day 0 is the day the first egg in the clutch hatched). In 1988 the procedure was different, in that three clutches of different size were manipulated to one common size. Apart from this, the manipulation was similar to the other years. Chicks were ringed at day 7 with uniquely numbered rings, and were weighed to the nearest 0.1 $\mathrm{g}$ on day 15 (when they are at approximately their fledging mass [van Balen 1973]). Parents were caught in the nest boxes and identified on $\sim$ day 7. After successfully fledging a first brood some pairs started a second brood, which was also monitored. The size of second broods was not manipulated. Because we have a control, a reduced, and an enlarged clutch that hatched on the same date, the possible effects on reproductive success due to difference in timing between groups are not part of the manipulation effect. A detailed description of the brood size manipulations is given by Tinbergen (1987).

Measure of density.-Density is defined as the number of pairs of breeding birds (based on the number of first broods) using nest boxes per hectare in the study area, with the density of boxes remaining constant through the study. The years in which the manipulations were carried out had densities of between 0.33 and 1.05 breeding pairs/ha. This is almost the entire range of densities in this population (Fig.1).

Possible biases in the experimental sample.-Comparing model predictions with the observed relationship between population mean clutch size and density is only valid if the experimental broods are an unbiased sample of the population. The clutches used in the experimental manipulations tended to be the most frequent clutch sizes in the year of manipulation, because three clutches of equal size and hatching date were used in the manipulation. Overall, after correcting for year, the original clutch size of the manipulated broods was 0.3 eggs larger than unmanipulated broods $\left(F_{1,1334}=\right.$ $7.46, P=0.006)$. The annual mean clutch size of manipulated broods was highly correlated with annual mean clutch size of all broods in the same year $(r=$ 0.93, $n=8, P<0.001)$, and the relationship between 

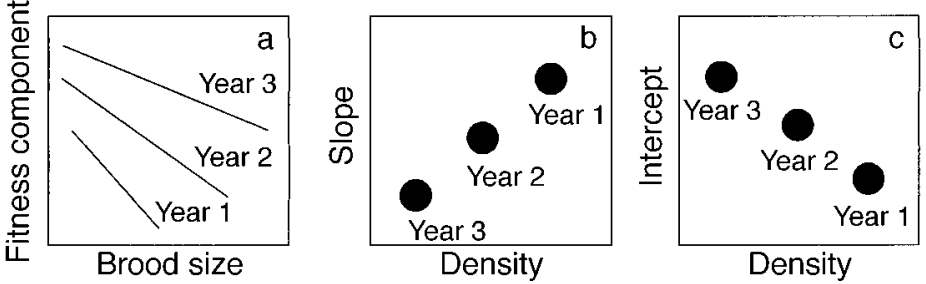

FIG. 2. Rationale for the statistical analysis of effects of brood size and density. (a) The effect of brood size and year are fitted (ANCOVA model), and this gives an estimate of the slope for each year when the interaction between year and brood size is significant) and intercept (when year as a main effect is significant). (b) The significant effects of year in interaction with brood size from the analysis depicted in (a) are subsequently regressed against the density. (c) The significant effects of year from the analysis depicted in (a) are subsequently regressed against the density. annual mean clutch size of manipulated broods and density did not differ between the period with experimental and nonexperimental years (ANCOVA: density: $F_{1,32}=15.2, P=0.005$; period: $F_{1,31}=0.09, P$ $=0.77$; period $\times$ density: $F_{1,30}=0.99, P=0.33$ ). There thus does not seem to be a bias in the manipulated broods in that these were differently affected by population density. Another possible bias is due to laying date, since Great Tit clutch size is negatively related to laying date (Verhulst et al. 1995). In our study population the effect of laying date on clutch size is independent of density (correlation of density and the slopes of the regression of clutch size on laying date for each year: $r_{\mathrm{s}}=0.004, n=24, P=0.99$ ), and no correlation was found between annual mean laying date and density in the period 1960-1994 $(r=-0.14, n=$ $35, P=0.42)$.

\section{Statistical analysis}

Rationale of the analysis.-The objective of the statistical analysis is to estimate the effect of brood size of the first brood and density on different fitness components: the proportion of chicks that fledged, the mean fledging mass per brood, the recruitment rate per fledgling, the proportion of pairs starting a second brood, and the survival rates of both male and female parents. However, the value of density was the same for all broods that were manipulated in the same year. Density therefore could not be used as an independent variable in a single analysis with brood size for each brood separately, without having the problem of pseudoreplication. We therefore estimated the effect of density in the following way: the effect of experimental brood size was estimated in a within-year analysis, using an ANCOVA in which year was treated as a categorical variable and brood size as a numerical variable (Fig. 2a). Years can differ in both the strength (i.e., slope) of the brood size effect, and in the level (i.e., intercept). If one or both of these year effects explained a significant part of the variation, the estimates of either the significant slopes, intercepts, or both for each year were regressed against the density in that year in the between-year analysis (Fig. 2b, c). If density explained a significant part of the variation of one or both of these annual estimates, the regression equation was substituted in the equation from the ANCOVA. The effect of density on recruitment rate was analyzed similarly. Fledging mass and a factor for year were fitted in an ANCOVA, and the annual estimates of slope, intercept, or both were regressed against the density. The effects of brood size and density were expected to be nonlinear. We therefore included quadratic terms for brood size and density in the analyses.

Data selection.-We used only broods that fledged young in the fitness estimate. We believe that this is acceptable because the probability of complete nest failure was not affected by brood size, or the original clutch size (see Tinbergen and Daan 1990). No brood size effect was found on parental survival (see Results) and therefore the optimal clutch size will not be affected by the rate of nest failure (Charnov and Krebs 1974). A further reason to exclude failed broods is that parents might choose to abandon their manipulated brood and start a new brood if this yields a higher fitness (Verboven 1998), while the manipulation is aimed at forcing parents to raise the manipulated brood.

Treatments.—Broods were enlarged and reduced by approximately half the brood size. This experimental design results in a positive relation between the original clutch size and the brood size after manipulation. Thus also after manipulation the observed effects of brood size might be partly due to high-quality parents laying large clutches and being better able to raise young and raising larger young, rather than effects of brood size per se (Van Noordwijk and De Jong 1986). This experimental design therefore should not be analyzed with respect to final brood size, but rather to manipulation category (reduced, control, and enlarged), with the size of the original clutch included in the analysis (see Tinbergen and Daan 1990). Our aim is, however, to make a quantitative prediction of how clutch size and density affect fitness components. An analysis using manipulation categories does not suit this goal. To circumvent the problem that conclusions are drawn on the basis of an analysis that does not clearly separate effects of parental quality and clutch size, we present the analyses of the data using both manipulation categories as well as using brood size as a numerical variable. In both analyses the original clutch size was included. If in both sets of analyses there is an effect of brood size we use the analyses with final brood size as an approximation of the real effect of brood size. 
Parental survival.-Survival to the next year was measured as local survival, based on capture of breeding birds. Because not all adults are caught during a season, survival should be corrected for differences in capture probability. Capture probability was calculated on adults that were known to be alive in year $t+1$, from captures in year $t+2$ and later. Of these individuals the capture rate in year $t+1$ could be calculated using logistic regression, using GLIM (Royal Statistical Society 1992). When capture probabilities differed significantly between manipulation categories, we analyzed survival while correcting for the differences in capture probability using SURPH (Smith et al. 1994). When there were no significant differences in capture probability, no correction was made and survival was analyzed using logistic regression (in GLIM).

Recruitment.-Recruitment rates are highly variable between years due to weather influences and the irregular occurrence of beech mast (Perrins 1966, Verhulst 1992). If we use only a small number of years to calculate recruitment rates, the analysis would be strongly affected by these factors. Therefore we estimated the average recruitment rate as function of fledging mass and density using 18 years of data from this population, constituting 8962 fledglings. Since brood size affects recruitment rates only through its effect on fledging mass, we can use nonexperimental data in the analysis of fledging mass on recruitment rate (Tinbergen and Boerlijst 1990). Capture probability of young birds known to be alive in their second year $(N=125)$ did not differ between years $\left(\chi_{15}^{2}=13.7, P=0.55\right)$, and was not related to fledging mass $\left(\chi_{1}^{2}=0.11, P=0.74\right.$; interaction mass $\times$ year: $\left.\chi_{14}^{2}=5.07, P=0.98\right)$, and therefore recruitment rates were not corrected for capture probability.

Second broods. - The second variable that is difficult to estimate from the limited number of years with brood size manipulations, is the clutch size of the second brood. Therefore we analyzed the relationship between the annual mean clutch size of second broods and population density for all years from 1960 to 1995 . In the model, the nestling survival and recruitment rate of second broods were assumed to be the same as those for the first brood. This might not be true (see Verboven and Visser 1998), but no brood size manipulations with second broods have been carried out to estimate these relationships properly. Because the contribution of second broods to overall fitness turns out to be relatively small, this simplification will not have a large effect on the predictions.

Testing procedure.-All analyses were two-tailed, and were performed using GLIM, Statistix (Analytical Software 1996), or SURPH. The testing procedure started with a statistical analysis including the main effects and the two-way interactions. Terms were excluded from the analysis, starting with the interaction terms. Terms were considered to be significant if the exclusion resulted in a significant decrease in deviance in the presence of all other terms on the same hierarchical level and all significant effects on a higher hierarchical level. Nonsignificant interaction terms were excluded before testing the main effects. If an interaction term including a numerical variable was significant, we did not test the significance of the main effect of this numerical variable separately. Proportional data such as nestling and parental survival, recruitment rate, and the probability of producing a second brood were analyzed using logistic regression, which takes the binomial nature of the data into account.

\section{Calculation of the optimal clutch size and the confidence intervals}

We calculated an approximate confidence interval around our predicted optimal clutch size response to density by: (1) drawing a value from a standard normal distribution for each estimated parameter in the model, (2) multiplying these values with the standard error for the mean of each parameter estimate, (3) calculating the optimal clutch size for each density, and (4) repeating this procedure 5000 times. The $95 \%$ confidence interval is the extreme values from these simulations after discarding the $2.5 \%$ highest and lowest values.

\section{Sensitivity analysis}

To investigate which stage of the reproductive cycle was most sensitive to density effects, we separated the analyses in four stages: (1) nestling stage of first brood, (2) second brood stage, (3) recruitment stage, and (4) parental survival. The nestling stage is based upon two separate statistical analyses, i.e., the effect on nestling survival and on fledging mass. The relative effect of density on the optimal clutch size response in each of the separate fitness components was investigated. The procedure was that the effect of brood size and year were again estimated in an ANCOVA, but the year effects were averaged in order to get an estimate for the average year, without taking density into account. The optimal clutch size response was calculated subsequently with the new estimate for the brood size effect without density for this single fitness component, while the effects of brood size and density were included in the other three fitness components. This analysis was performed for each of the four stages. Comparing the optimal clutch size response of these alternative models with the full model will reveal for which fitness component density affects clutch size most strongly.

\section{Selection differentials}

To investigate whether there is selection for clutch size, we calculated the annual standardized selection differential for clutch size as [annual mean clutch size weighed for the number of recruits per nest - annual mean clutch size of whole population]/[standard deviation of annual mean clutch size] (Falconer 1981). For this analysis only nonmanipulated clutches have 

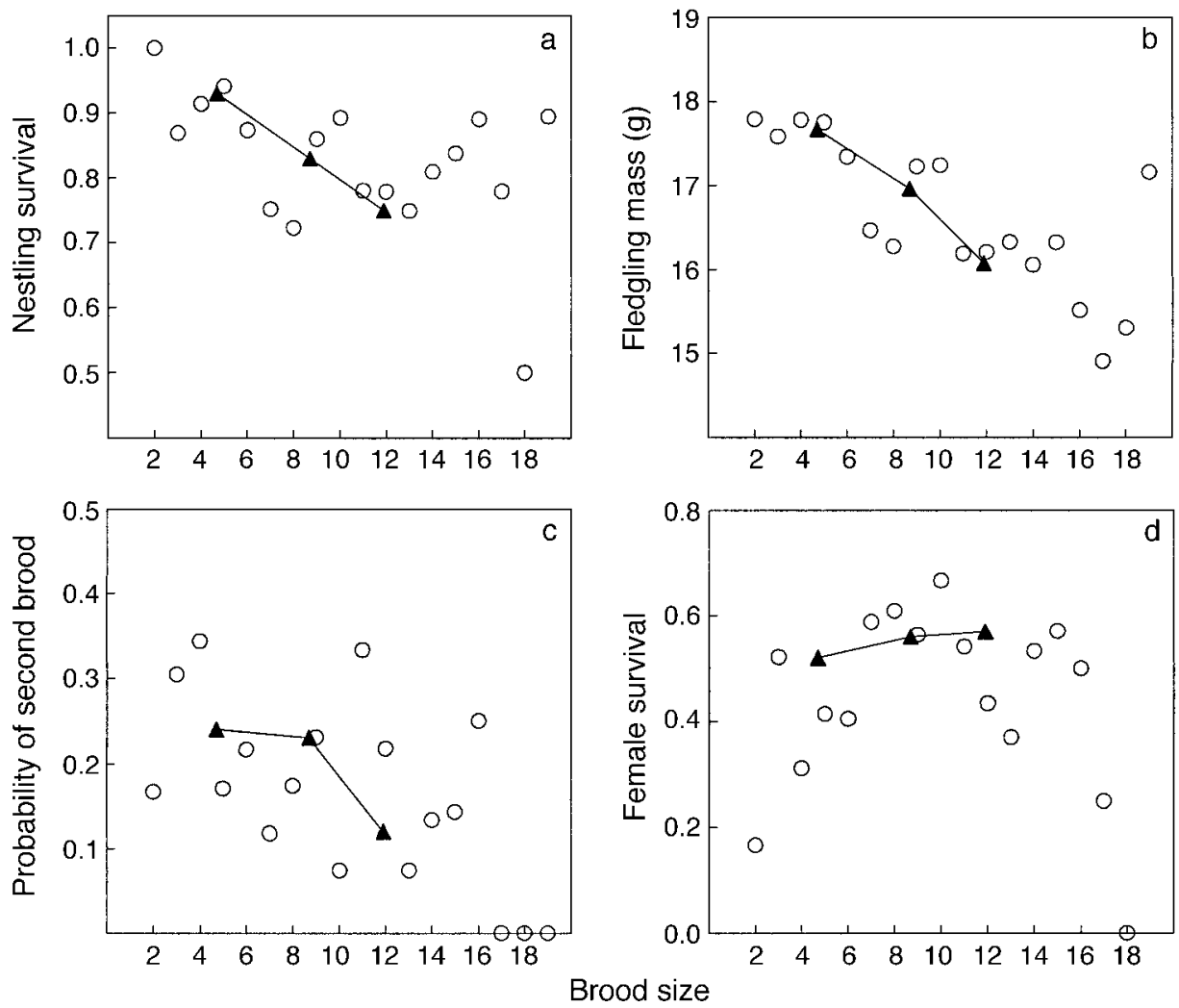

FIG. 3. The effect of experimental variation in brood size on the fitness components. For each component, the average values for each final brood size (circles) and for each manipulation category (triangles) are given. The average brood size for each category is indicated on the $x$-axis. The plots show (a) nestling survival, (b) fledging mass, (c) probability of producing a second brood, and (d) female survival (for manipulation categories corrected for capture rates, see Results). See Tables $1-3$ for statistical analyses.

been used. We calculated selection differentials only for years with at least 20 unmanipulated broods, which produced at least five recruits in the next year. If the observed clutch size response is not adaptive we expect that the standardized selection differential correlates with density.

\section{RESUlTS}

\section{Experimental results}

Fitness of the first brood.-Nestling survival was lower in larger broods (Fig. 3a, Table 1). Years differed in how strongly nestling survival declined with brood size, but for small broods nestling survival approached 1 in all years (the intercepts did not vary among years). Enlarging the brood reduced nestling survival more in higher density years (i.e., the estimates of the slopes were negatively correlated with population density, Fig. 4a).

Fledglings from larger broods had a lower average fledging mass (Fig. 3b, Table 1a). Years differed in average fledging mass and in the rate at which fledging mass declined with brood size. The penalties of having large clutches were stronger in high-density years (i.e., the annual estimate of the slope was negatively cor- related with density, Fig. 4b). The annual estimates of intercept were not correlated with density.

If the results of both analyses are compared with the analyses in which manipulation category was used instead of brood size (Table 1), the only difference is that the interaction between year and brood size on the fledging mass was not significant in the analysis using manipulation categories. The difference is caused by the way the statistical analyses are simplified, and do not seem to have biological meaning (see legend of Table 1 for more details).

Recruitment rate increased nonlinearly with fledging mass (Table 2), and in low density years fledglings with the same mass recruited better than in high-density years (i.e., years had different intercepts which were negatively correlated with density, Fig. 4d).

Fitness of the second brood.-The proportion of birds producing a successful second brood was negatively affected by brood size (Fig. 3c, Table 1a). The strength of this decrease did not, but the average proportion did differ between years. Within the same brood size, birds in high-density years were less likely to produce a successful second brood (the intercept was negatively correlated with the density, Fig. 4c). Com- 
TABLE 1. Analysis of covariance of the effect of brood size manipulations, original clutch size, and year on fledging mass, nestling survival, and the probability of producing a successful second brood.

\begin{tabular}{|c|c|c|c|c|c|c|c|c|c|}
\hline \multirow[b]{2}{*}{ Variable } & \multicolumn{3}{|c|}{ Nestling survival } & \multicolumn{3}{|c|}{ Fledging mass } & \multicolumn{3}{|c|}{ Second brood probability } \\
\hline & $F$ & df & $P$ & $F$ & df & $P$ & $\chi^{2}$ & df & $P$ \\
\hline \multicolumn{10}{|c|}{ a) Brood size as continuous variable } \\
\hline Brood size & n.a. & & & n.a. & & & 10.4 & 1 & 0.001 \\
\hline$(\text { Brood size })^{2}$ & 0.95 & 1,350 & 0.330 & 2.87 & 1,327 & 0.091 & 1.23 & 1 & 0.267 \\
\hline Clutch size & 6.32 & 1,351 & 0.012 & 0.87 & 1,328 & 0.352 & 5.51 & 1 & 0.019 \\
\hline Year & 1.79 & 7,351 & 0.088 & 2.13 & 7,328 & 0.040 & 68.6 & 7 & $<\mathbf{0 . 0 0 1}$ \\
\hline Brood size $\times$ Year & 2.44 & 7,343 & 0.019 & 0.86 & 7,320 & 0.007 & 3.12 & 7 & 0.874 \\
\hline Clutch size $\times$ Year & 0.70 & 7,343 & 0.675 & 1.07 & 7,320 & 0.383 & 1.81 & 7 & 0.970 \\
\hline$(\text { Brood size })^{2} \times$ Year & 1.75 & 7,336 & 0.096 & 0.97 & 7,314 & 0.454 & 6.75 & 7 & 0.455 \\
\hline \multicolumn{10}{|c|}{ b) Brood size as categorical variable } \\
\hline Manipulation & 28.4 & 2,357 & $<\mathbf{0 . 0 0 1}$ & 55.2 & 2,334 & $<\mathbf{0 . 0 0 1}$ & 8.38 & 2 & 0.015 \\
\hline Clutch size & 1.95 & 1,357 & 0.163 & 21.6 & 1,334 & $<\mathbf{0 . 0 0 1}$ & 1.49 & 1 & 0.222 \\
\hline Year & 5.83 & 7,357 & $<\mathbf{0 . 0 0 1}$ & 13.3 & 7,334 & $<\mathbf{0 . 0 0 1}$ & 72.8 & 7 & $<\mathbf{0 . 0 0 1}$ \\
\hline Manipulation $\times$ Year & 2.31 & 14,336 & 0.005 & 1.31 & 14,313 & 0.199 & 7.26 & 14 & 0.924 \\
\hline Clutch size $\times$ Year & 0.583 & 7,336 & 0.771 & 1.22 & 7,313 & 0.291 & 2.87 & 7 & 0.897 \\
\hline
\end{tabular}

Notes: The effect on fledging mass is analyzed with a normal error distribution. Nestling survival and the probability of producing a second brood both have a binomial error distribution. The models on nestling survival were overdispersed, and Williams' correction was therefore used (Crawley 1993). In panel (a), brood size is treated as a continuous variable, in panel (b), brood size is treated as a categorical variable with three levels (reduced, control, enlarged). See "Statistical analyses" for rationale of giving both analyses. If the interaction between brood size and year was significant, no effect of brood size is given separately. When the interaction of manipulation $\times$ year in the analysis of fledging mass was tested without the effect of year $\times$ clutch size, this interaction was significant. This suggests that there is only a minor discrepancy between the categorical analysis and the continuous analysis. $P$ values $<0.005$ are shown in bold type.
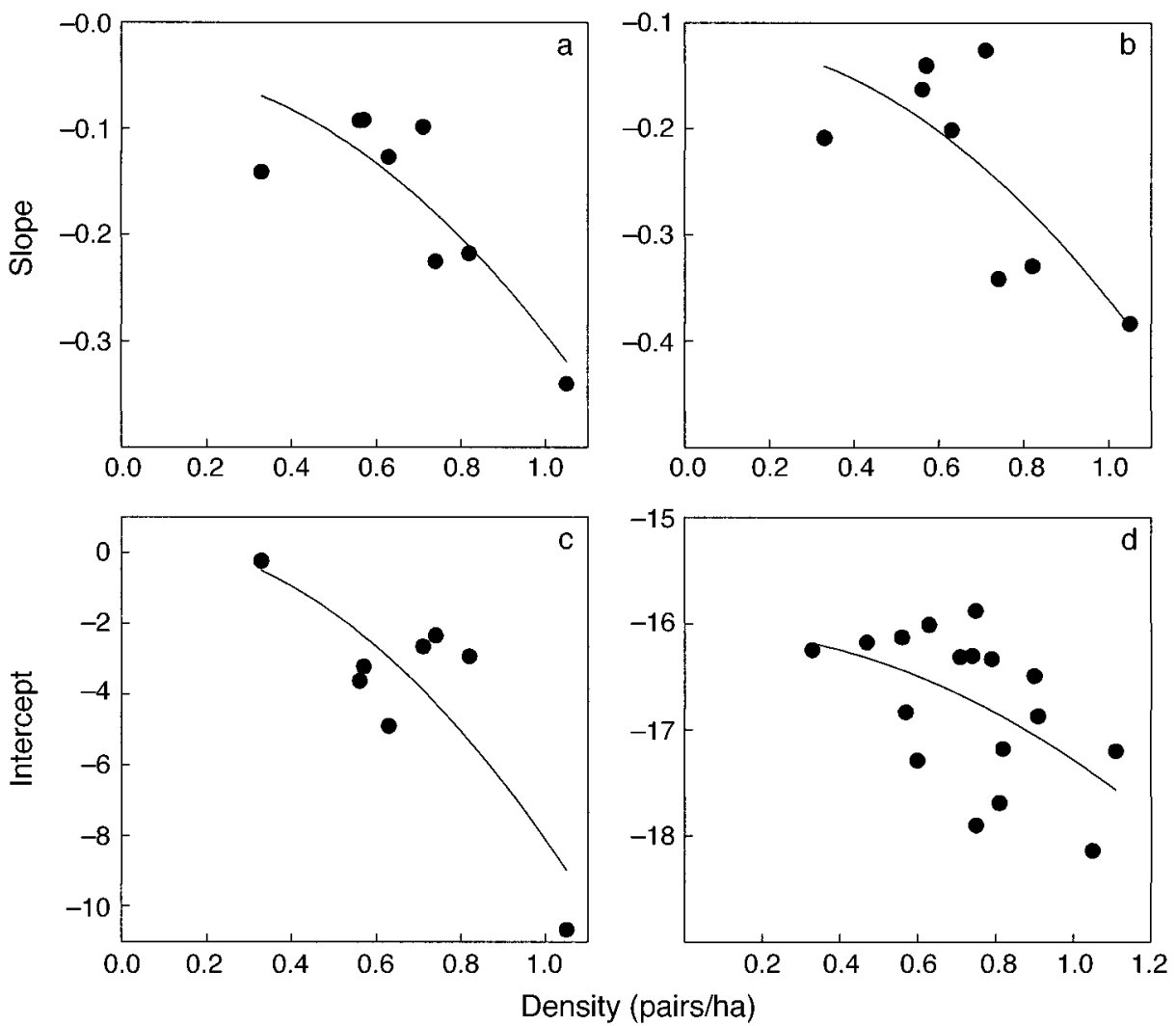

FIG. 4. Effect of density on the annual value of the mean level (intercept) or the strength of the effect (slope) of brood size on fitness components. (a) The strength of the reduction in nestling survival with brood size, which correlates with $(\text { density })^{2}\left(F_{1,6}=16.1, P=0.007\right)$. (b) The strength of the reduction in fledging mass with brood size differs between years, and the estimate of this slope correlates with (density) $)^{2}\left(F_{1.6}=7.15, P=0.037\right)$. (c) The average probability of producing a second brood decreases with (density) ${ }^{2}\left(F_{1,6}=13.52, P=0.010\right)$. (d) The average effect of nestling mass on the local recruitment probability declines with (density) $)^{2}\left(F_{1,6}=6.45, P=0.022\right)$. 
TABLE 2. Analysis of covariance with binomial errors of the effect of fledging mass and year on recruitment rate.

\begin{tabular}{lcrr}
\hline \hline \multirow{2}{*}{\multicolumn{1}{c}{ Variable }} & \multicolumn{3}{c}{ Recruitment probability } \\
\cline { 2 - 4 } & $\chi^{2}$ & $\mathrm{df}$ & \multicolumn{1}{c}{$P$} \\
\hline Fledging mass & 13.24 & 1 & $<\mathbf{0 . 0 0 1}$ \\
(Fledging mass) $^{2}$ & 9.30 & 1 & $\mathbf{0 . 0 0 2}$ \\
Year & 217.9 & 17 & $<\mathbf{0 . 0 0 1}$ \\
Fledging mass $\times$ Year & 14.27 & 17 & 0.648 \\
(Fledging mass) $^{2} \times$ Year & 20.30 & 17 & 0.259 \\
\hline
\end{tabular}

Notes: The analysis includes 18 years, in which 8926 fledglings were weighed. $P$ values $<0.05$ are shown in bold type.

parison of the analyses using brood size and manipulation category (Table 1) yielded qualitatively similar results.

The average clutch size of second broods was negatively correlated with population density, using the data from 1960 to $1995\left(F_{1,35}=11.8, P=0.002\right)$.

Parental survival.-Parental survival rates are based upon recapture in the next season. The capture probability was significantly higher for females than for males $\left(\chi_{1}^{2}=8.43, P=0.004\right.$, males 0.79 , and females $0.95)$, and therefore the sexes were analyzed separately. In males the capture probability did not differ between manipulation categories, nor did their survival (Table $3 \mathrm{~b})$. The analysis using brood size yielded the same result (Table 3a). Female capture rates differed between the manipulation categories $\left(\chi_{2}^{2}=6.03, P=0.049\right.$, reduced: 0.86; control: 1.0; enlarged: 0.93), and survival rates for the categories were adjusted accordingly using SURPH (Smith et al. 1994). After correction, no effect of manipulation was found on female survival (Table 3b, Fig. 3d). Paradoxically, the capture rates were not affected by brood size or its quadratic term $\left(\chi_{1}^{2}=\right.$ $\left.1.01, P=0.31, \mathrm{BS}^{2}: \chi_{1}^{2}=0.04, P=0.84\right)$. The female survival rates with respect to brood size were therefore analyzed on uncorrected survival, which was significantly related to brood size, brood $s^{2}{ }^{2}$, clutch size, and year (Table 3a, Fig. 3d). From this analysis it seems that females caring for smaller and larger broods had lower survival than females feeding intermediate sized clutches.

The problem is that the analyses on female survival using manipulation categories and brood size gave different results. The analysis using manipulation categories is considered better, because this follows the experimental setup (see Methods) and is in accordance with data on other experiments in the same species (Pettifor et al. 1988). Furthermore, later laying females have slightly smaller clutches in this population, and might have lower survival (see Verhulst et al. 1995). The analysis using final brood size as independent variable suffers from this covariation, and hence we prefer to follow the outcomes from the categorical analysis. Also, the estimates of the year effects were not correlated with the annual density for males and females (males, $F_{1,7}=0.00$; females, $F_{1,7}=0.04$ ).

\section{Model predictions: the full model}

We used the results from the brood size manipulations to parameterize the equations of the optimality model (see Appendix). Parental survival $\left(S_{\mathrm{P}}\right)$ was not clearly affected by either density or the clutch size of the first brood $\left(C_{1}\right)$. Because $S_{\mathrm{P}}$ is not related to $C_{1}$, Eq. 1 can be simplified to include only the sum of recruits of the first and the second brood. We can now solve Eq. 1 numerically and calculate optimal clutch sizes under different densities.

The optimal size of the first clutch in the model decreased at higher density (Fig. 5a). This is due to the number of recruits of first and second broods being

TABLE 3. Analysis of covariance with binomial errors of the effect of brood size manipulations, original clutch size, and year on local parental survival.

\begin{tabular}{|c|c|c|c|c|c|c|}
\hline \multirow[b]{2}{*}{ Variable } & \multicolumn{3}{|c|}{ Females } & \multicolumn{3}{|c|}{ Males } \\
\hline & $\chi^{2}$ & df & $P$ & $\chi^{2}$ & $\mathrm{df}$ & $P$ \\
\hline \multicolumn{7}{|c|}{ a) Brood size treated as continuous variable } \\
\hline Brood size & 4.77 & 1 & 0.029 & 0.59 & 1 & 0.442 \\
\hline$(\text { Brood size })^{2}$ & 4.11 & 1 & 0.043 & 0.66 & 1 & 0.417 \\
\hline Clutch size & 6.53 & 1 & 0.011 & 0.33 & 1 & 0.566 \\
\hline Year & 26.4 & 7 & 0.001 & 22.04 & 7 & 0.003 \\
\hline Brood size $\times$ Year & 8.91 & 7 & 0.259 & 4.80 & 7 & 0.771 \\
\hline Clutch size $\times$ Year & 10.9 & 7 & 0.143 & 2.22 & 7 & 0.947 \\
\hline$(\text { Brood size })^{2} \times$ Year & 7.28 & 7 & 0.400 & 7.40 & 7 & 0.388 \\
\hline \multicolumn{7}{|c|}{ b) Brood size treated as categorical variable } \\
\hline Year & 30.0 & 7 & 0.001 & 15.8 & 7 & 0.027 \\
\hline Manipulation & 1.14 & 2 & 0.56 & 0.69 & 2 & 0.708 \\
\hline Clutch size & 6.18 & 1 & 0.013 & 0.77 & 1 & 0.380 \\
\hline Manipulation $\times$ Year & 24.1 & 14 & 0.045 & 10.4 & 14 & 0.732 \\
\hline Clutch size $\times$ Year & 8.02 & 7 & 0.33 & 4.84 & 7 & 0.679 \\
\hline
\end{tabular}

Notes: In (a), brood size is treated as a continuous variable; in (b), brood size is treated as a categorical variable with three levels (reduced, control, enlarged). The survival rates of females are corrected for differences in capture rate between the manipulation categories using SURPH (see Statistical analysis). $P$ values $<0.05$ are shown in bold type. 
FIG. 5. (a) The annual mean clutch size in nonexperimental years as a function of the density (thick dashed line: best linear fit through the long-term data; see Fig. 1), and the prediction from the clutch size optimality model (solid line $=$ model prediction; dashed lines $=$ upper and lower confidence intervals). (b) Predictions of the optimal clutch size response to density, with the effect of density excluded from different stages of the reproductive cycle (solid line $=$ no density effect in the nest stage; dashed line $=$ no density effect in the recruitment stage; dotted line $=$ no density effect on the probability of producing a second brood).

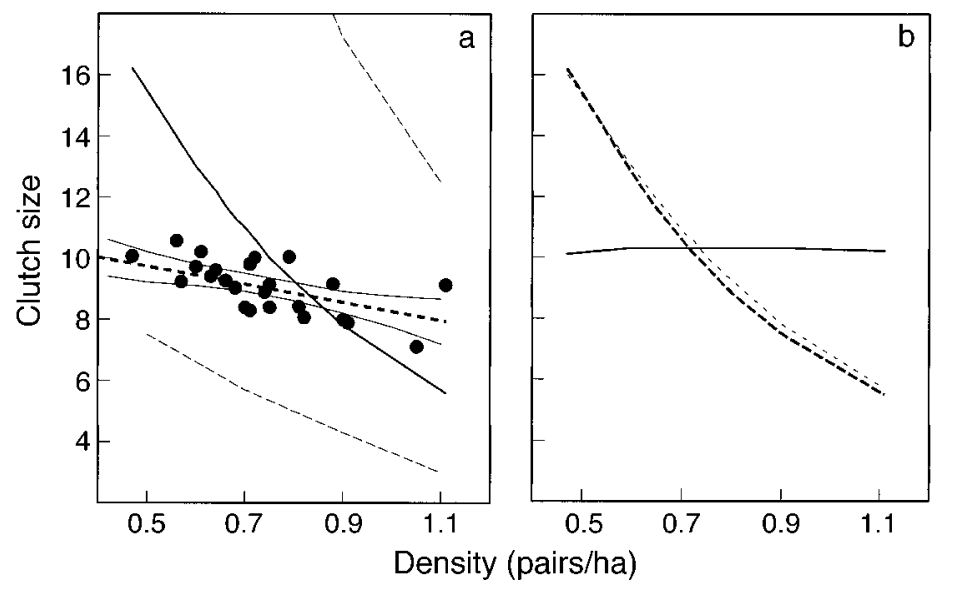

both a function of density and clutch size of the first brood $\left(C_{1}\right)$. The value of the first brood is a quadratic function of brood size (Fig. 6a), while the value of the second brood is negatively related to the size of the first brood (Fig. 6b). The latter effect occurs because the probability of producing a successful second brood declines with $C_{1}$. Density lowers the fitness summed over both broods (Fig. 6c).

The boundaries of $95 \%$ confidence interval give the most extreme slopes given the errors around all estimates. The decrease in the predicted optimal clutch size with population density is significantly different from zero if the $95 \%$ confidence intervals were taken into account (minimum slope $<0$ ). Although the observed values lie well within the predicted $95 \%$ confidence interval, the density dependence of clutch size in the unmanipulated years of the long-term study is less pronounced than predicted by the optimality model. The slope of the regression $(-2.94 \pm 0.84$ eggs per 1.0 pair/ha density increase; mean $\pm 1 \mathrm{SE}$ ) is significantly larger than the maximum slope as predicted by the 5000

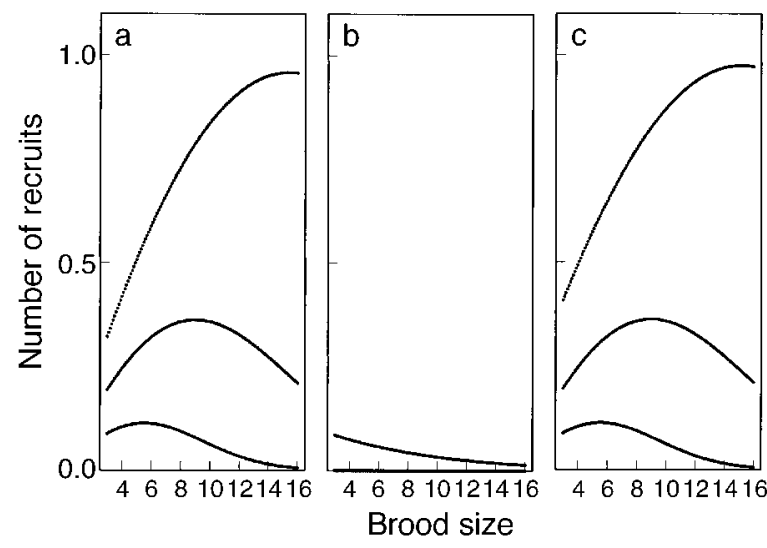

FIG. 6. Expected number of recruits as function of brood size and density for: (a) the first brood, (b) the second brood and (c) the first and second broods combined. In all graphs, the different lines refer to densities of $0.3,0.6$, and 0.9 pairs/ ha (from top to bottom). simulations with the observed standard errors: the largest slope found is -3.0 , and the upper boundary of the $95 \%$ confidence interval is -7.2 . Thus, the confidence intervals of observed and predicted slopes did not overlap. In conclusion, we showed that the birds adjusted their clutch size to density, but to a smaller extent than our optimality model predicted.

\section{Relative importance of density in different reproductive stages}

The relative importance of density in different stages of the reproductive cycle on the optimal clutch size is depicted in Fig. 5b. When density was not included in the effect of brood size on the nestling stage (survival and mass), the optimal clutch size is independent of density. The same treatment for the probability of producing a second brood and the recruitment rates did not differ from the prediction of the full model. Thus the predicted optimal clutch size response to density was completely caused by the effect of density during the nestling phase.

\section{Selection for clutch size and population density}

The optimal reaction norm is steeper than the observed, which would lead to selection for larger clutches at low, and for smaller clutches at high densities (Fig. 7a). To calculate the direction of selection at different densities we use the standardized selection differential for clutch size. Negative selection differentials mean that there is selection for smaller clutches, while positive selection differentials show selection for larger clutch size (Fig. 7a). However, although there was considerable variation in standardized selection differentials for clutch size, it was not negatively correlated with density, suggesting that birds would not have done better by adjusting their clutch size more to the density than we observed (Fig. 7b).

\section{DISCUSSION}

The optimal clutch size of Great Tits in the study population declined with increasing density. This was 


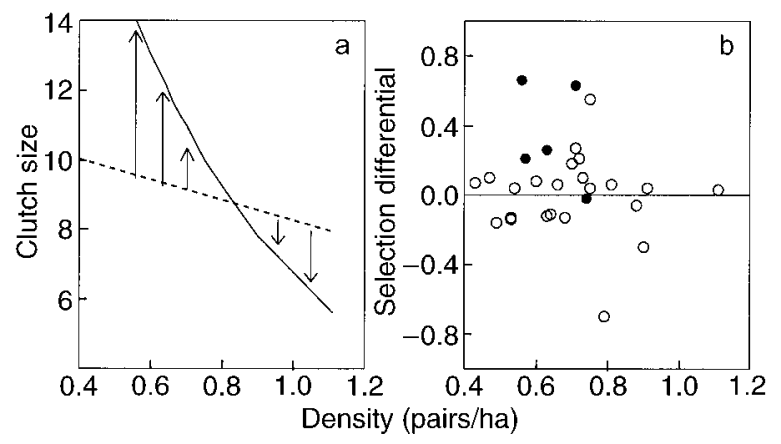

FIG. 7. (a) The expected standardized selection differential for clutch size as a function of population density. The solid line is the predicted optimal clutch size, and the dashed line is the observed regression line (see Fig. 5a). (b) The observed standardized selection differential for clutch size as a function of population density. No significant correlation was found between the selection differential and the density $\left(F_{1,25}=0.098, P=0.76\right)$, but the experimental years had larger selection differentials than the nonexperimental years $\left(F_{1,26}=8.53, P=0.007\right.$; period $\times$ density interaction, $F_{1,24}$ $=0.54, P=0.47)$. Solid circles $=$ experimental years; open circles $=$ years in which no brood size experiments were carried out.

shown in an optimality model parameterized with experiments in which the fitness consequences of experimental variation in brood size were related to natural variation in density. In this population, clutch size, nestling growth, nestling survival, and recruitment rate, as well as the parents' probability of producing a second brood, all decreased with increasing density. Predicted and observed clutch size response to density resembled each other qualitatively, but the predicted optimal clutch size response was considerably steeper than the observed relationship between the annual mean clutch size and population density (Fig. 5a).

\section{Nonoptimal behavior?}

The model predicted that at low densities birds should lay more, and at high densities fewer, eggs than observed to maximize fitness. If the observed clutch size response to density in our study area is indeed nonoptimal (see Dhondt et al. 1990, Verhulst 1995), then at low densities there should be selection for larger than observed clutches, while at high densities there should be selection for smaller clutches. However, selection for clutch size was independent of density (Fig. $7 b$ ), which suggests that the tits indeed optimized their clutch size on an annual basis with respect to density. This leads to the conclusion that the model is not an adequate description of the important selection pressures and constraints. We explore two possible types of explanations for this discrepancy: experimental bias and additional constraints.

\section{Experimental bias}

One reason for the difference between observation and prediction is that experimental years were not rep- resentative of the whole study period. An indication for this is that the available selection differentials in experimental years were significantly different from those in nonexperimental years, and show that there was selection for larger clutches in experimental years with a low density (Fig. 7b). This can explain why the predicted clutch size is higher than observed in lowdensity years, because in these years the birds did better by laying a larger than observed clutch. Thus the model may be biased because manipulations were carried out in nonrepresentative years.

A further reason for the difference between prediction and observation might be that the manipulations were not set up to analyze with respect to final brood size (see Methods). Because we manipulated a fixed proportion of the brood, a correlation existed between original clutch size and final brood size. If clutch size is adjusted to phenotypic quality, then parents raising small experimental broods were on average of lower quality than parents raising large experimental broods. The consequence of a correlation between phenotypic quality and experimental brood size is that the measured relationships between fitness components and brood size are probably steeper than they actually are. If the correctly measured relationships would indeed be less steep, the predicted optimal clutch size response to density would also be less steep. The discrepancy between observation and prediction (Fig. 5a) might thus be the result of the way we carried out the brood size manipulations.

\section{Additional constraints}

Optimality models in behavioral ecology are used to test whether all important constraints are identified (Krebs and Kacelnik 1991). One of the possibly important constraints not included in the model is the cost of egg-production and incubation. Manipulations were performed after hatching and hence they tested the fitness consequences of the number of eggs hatched, not of the number of eggs laid. Recent experiments suggest that the energetic and fitness costs of these activities may be substantial (Moreno and Sanz 1994, Oppliger et al. 1996). Parents which receive extra chicks do better than if they have to produce and incubate them (Heany and Monaghan 1995, Monaghan et al. 1995, Monaghan and Nager 1997), although this has not been shown in the Great Tit (M. E. Visser and C. M. Lessells, unpublished manuscript). Perrins and McCleery (1994) showed that in the long-term study of Great Tits at Oxford the mean egg size is negatively correlated with population density, suggesting that the fitness costs of producing eggs may be positively related to density. A different fitness cost of egg-laying is the delay of an extra day with each additional egg laid, which imposes fitness loss when a decline in fitness with laying date exists (Pettifor et al. 1988, Verhulst et al. 1995). The consequence of such a delay is that fitness declines progressively with clutch size, resulting in smaller op- 
timal clutch sizes. Alternatively, females can advance egg-laying one day for each additional egg, which may incur a fitness cost to herself. The cost of egg-laying is the most likely selection pressure not included in the model, and the consequence is that the optimal clutch size will be lower than predicted by our experiments. This cost can only account for the smaller observed clutches at lower densities, not for the larger clutches at high densities.

\section{The cause of density dependence of clutch size}

The nature of the density-dependent processes underlying the fitness effects are not known in this population. In another Great Tit population, nest predation was an important density-dependent process, with larger natural clutches having a higher probability of being eaten at high densities (Krebs 1970). In our study area nest predation was mostly absent. Effects of ectoparasites might be density dependent (Newton 1998). In our study it is probably not important, since old nests were always removed after the breeding season, which considerably reduces the parasite burden (Møller 1989). Our nest box study can therefore be considered an experimental situation, which strongly reduces effects of nest predation and parasitism. Hence the density-dependent effects are likely to be caused by competition for resources during the nestling period, but effects of competition, predation, and parasitism after chicks have left the nest cannot be excluded.

The sensitivity analysis showed that the predicted density dependence of clutch size was completely explained by the effect of density on how brood size affected nestling growth and survival. This can also be seen from the statistical analysis, as only for these two factors the slope of the brood size effect was negatively associated with density. (In the other cases the intercepts were density dependent.) We have good evidence that food availability affects fledging mass in this population, as shown by artificial food supplementation (J. M. Tinbergen, unpublished data; see also Arcese and Smith 1988, Tinbergen and Boerlijst 1990). Thus the amount of food nestlings receive is regarded as at least one of the density-dependent factors causing the decrease in optimal clutch size with density. This suggests that clutch size is tuned to competition on a local scale, such as variation in territory size (see, e.g., McCleery and Perrins 1985, Petersen and Best 1987, Bollman et al. 1997, Both and Visser 2000). Individual variation in resource availability due to variation in territory size may explain within-year variation in clutch size, similar to the way density explains betweenyear variation in clutch size.

\section{Adaptation and population dynamics}

Density dependence is one of the key concepts in population ecology because it provides the basic feedback regulating numbers (see, e.g., Nicholson 1933, Lack 1954, Murdoch 1994, Sutherland 1996a, b, Newton 1998). Most work on density dependence is based upon observed patterns in populations, the result of individuals behaving in different ways under different population densities. The theoretical framework that explains why individuals behave in certain ways is evolution by means of natural selection (Darwin 1859), and the same framework can be used to explain population patterns as well. The link between density dependence and natural selection is that both are, to a large extent, driven by competition for resources. Natural selection equips organisms with reaction norms that maximize their fitness, and the emerging pattern on the population is, among others, density dependence. The advantage of the optimization approach is that it does not only consider how individuals behave under prevailing circumstances, but in addition how behavior might change due to microevolution in response to environmental changes (Sutherland 1996b).

In our study the optimization approach yielded the insight that density dependence of clutch size is primarily an adjustment to the number of nestlings parents can feed, and hence food competition during this period is important. Parents decide about their clutch size a couple of weeks before nestlings are in the nest. Hence they have to make a prediction about future food density and the density of competitors this food has to be shared with (van Noordwijk and Müller 1994, van Noordwijk et al. 1995). This means that the way individuals assess their local circumstances is crucial to clutch size optimization. In the case that a change in the environment affects the relation between the cues used and the relevant environmental factor, an inadequate response may result (Visser et al. 1998). Although individuals might thus be constrained in whether they can respond flexibly to these (directional) changes in environmental conditions, optimization models can help to predict in which direction the response to selection goes. This approach can contribute to our knowledge on population dynamics by incorporating evolutionary dynamics into the population framework.

A strong aspect of the optimization approach is that the consequences of population density are calculated over a lifetime, and hence will give accurate measurements of competition during different periods in the lifecycle. In this study we showed that clutch size is adjusted to circumstances during the nestling stage and subsequent survival of fledglings. Thus the effect of reducing clutch size at higher densities is a reduction in nestling number, which increased survival and growth of nestlings, and their subsequent survival prospects after leaving the nest. Therefore, adaptive clutch size reduction in high-density years leads to reduced competition in later stages. Key-factor analysis used to determine the strength of density-dependent effects during different periods during the life cycle (Varley and Gradwell 1960) will in such a case overestimate the strength of density-dependent processes during the egg-laying stage, and underestimate the effect during 
the nestling stage. Thus by adjusting reproductive decisions to future levels of competition, birds make it more difficult for us to measure the real extent of density-dependent processes. We extend the population ecology approach by integrating effects of competition over the whole life cycle, and thereby contribute to a better understanding of the important process of population regulation.

\section{Conclusion}

The density-dependent response in clutch size was shown to be adaptive for the average individual in the population. The observed density dependence of the annual mean clutch size was, however, less strong than predicted from an optimality model. Selection for clutch size was, however, not correlated with density, suggesting that the birds behaved optimally, and that the model either lacked some important constraints, or that not all assumptions in the model were valid. We suggest that both may play a role, but we have only an explanation for why the clutch size is smaller than expected at low densities. A sensitivity analysis revealed that the density dependence of predicted optimal clutch size was caused entirely by the effect of density in the nestling stage.

\section{ACKNOWLEDGMENTS}

Many people assisted during the fieldwork, of whom Hans van Balen and Jan Visser deserve special attention because they managed the long-term project, made the database easily accessible, and did a considerable amount of the field work. Many students helped with carrying out the brood size experiments in the different years. Sichting 'Het Nationale Park de Hoge Veluwe' kindly gave permission to work on their property. Comments on earlier versions of the manuscript by Kate Lessells, Arie van Noordwijk, Robert St. Clair and an anonymous referee greatly improved the paper. This is publication number 2658 NIOO Centre for Terrestrial Ecology, Heteren, The Netherlands.

\section{Literature Cited}

Analytical Software. 1998. Statistix for Windows version 2.0. Analytical Software, Tallahassee, Florida, USA.

Arcese, P., and J. M. N. Smith. 1988. Effects of population density and supplemental food on reproduction in Song Sparrows. Journal of Animal Ecology 57:119-136.

Bollmann, K, H. U. Reyer, and P. A. Brodmann. 1997. Territory quality and reproductive success: can water pipits Anthus spinoletta assess the relationship reliably? Ardea 85:83-98.

Both, C. 1998a. Density dependence of clutch size in Great Tits: habitat heterogeneity or individual adjustment. Journal of Animal Ecology 67:659-666.

Both, C. 1998b. Experimental evidence for density dependence of reproduction in Great Tits. Journal of Animal Ecology 67:667-674.

Both, C., J. M. Tinbergen, and A. J. van Noordwijk. 1998 Offspring fitness and individual optimization of clutch size. Proceedings of the Royal Society of London, Series B 265 : 2303-2307.

Both, C. and M. E. Visser 2000. Breeding territory size affects fitness: an experimental study on competition at the individual level. Journal of Animal Ecology, in press.

Charnov, E., and J. R. Krebs. 1974. On clutch size and fitness. Ibis 116:217-219.
Cooch, E. G., D. B. Lank, F. Cooke, and R. F. Rockwell 1989. Long-term decline in fecundity in a Snow Goose population: evidence for density dependence? Journal of Animal Ecology 58:711-726.

Crawley, M. J. 1993. GLIM for ecologists. Blackwell Scientific, Oxford, UK.

Daan, S., C. Dijkstra, and J. M. Tinbergen. 1990. Family planning in the kestrel Falco tinnunculus: the ultimate control of covariation of laying date and clutch size. Behaviour 114:83-116.

Darwin, C. 1859. On the origin of species by means of natural selection. Murray, London, UK.

Dhondt, A. A., F. Adriaensen, E. Matthysen, and B. Kempenaers. 1990. Nonadaptive clutch sizes in tits. Nature (London) 348:723-725.

Dhondt, A. A., B. Kempenaers, and F. Adriaensen. 1992. Density-dependent clutch size caused by habitat heterogeneity. Journal of Animal Ecology 61:643-648.

Drent, R. H., and S. Daan. 1980. The prudent parent: energetic adjustments in avian breeding. Ardea 68:225-252.

Falconer, D. S. 1981. Introduction to quantitative genetics. Second edition. Longman, New York, New York, USA.

Finke, M. A., D. J. Milinkovich, and C. F. Thompson. 1987. Evolution of clutch size: an experimental test in the House Wren (Troglodytes aedon). Journal of Animal Ecology 56: 99-114.

Gustafsson, L., and W. J. Sutherland. 1988. The cost of reproduction in the Collared Flycatcher Ficedula albicollis. Nature (London) 335:813-815.

Haywood, S., and C. M. Perrins. 1992. Is clutch size in birds affected by environmental conditions during growth? Proceedings of the Royal Society of London, Series B 249: 195-197.

Heany, V., and P. Monaghan. 1995. A within-clutch tradeoff between egg production and rearing in birds. Proceedings of the Royal Society of London, Series B 261:361365 .

Högstedt, G. 1980. Evolution of clutch size in birds: adaptive variation in relation to territory quality. Science 210:11481150 .

Källander, H. 1974. Advancement of laying of Great Tits by the provision of food. Ibis 116:365-367.

Kluyver, H. N. 1951. The population ecology of the Great Tit, Parus m. major. Ardea 39:1-135.

Krebs, J. R. 1970. Regulation of numbers in the Great Tit (Aves: Passeriformes). Journal of Zoology, London 162: 317-333.

Krebs, J. R., and A. Kacelnik. 1991. Decision making. Pages 105-136 in J. R. Krebs and N. B. Davies, editors. Behavioural Ecology; an evolutionary approach. Third edition. Blackwell Science, Oxford, UK.

Krebs, J. R., and C. M. Perrins. 1978. Behaviour and population regulation in the Great Tit (Parus major). Pages 23-47 in F. J. Ebling and D. M. Stoddard, editors. Population control by social behaviour. Institute of Biology, London, UK.

Lack, D. 1947. The significance of clutch size. Ibis 89-90: 302-352, 25-45.

Lack, D. 1954. The natural regulation of animal numbers. Clarendon Press, Oxford, UK.

Lessells, C. M. 1986. Brood size in Canada geese: a manipulation experiment. Journal of Animal Ecology 55:669-689.

Lessells, C. M. 1991. The evolution of life histories. Pages 32-68 in J. R. Krebs and N. B. Davies, editors. Behavioural ecology; an evolutionary approach. Third edition. Blackwell Science, Oxford, UK.

McCleery, R. H., and C. M. Perrins. 1985. Territory size, reproductive success and population dynamics in the Great Tit, Parus major. Pages 353-373 in R. M. Sibly and R. H. Smith, editors. Behavioural ecology. Blackwell, Oxford, UK. 
Møller, A. P. 1989. Parasites, predators and nest boxes: facts and artifacts in nest box studies of birds. Oikos 56:421.

Monaghan, P., M. Bolton, and D. C. Houston. 1995. Egg production constraints and the evolution of avian clutch size. Proceedings of the Royal Society of London, Series B 259:189-191

Monaghan, P., and R. Nager. 1997. Why don't birds lay more eggs? Trends in Ecology and Evolution 12:270-274.

Moreno, J., and J. J. Sanz. 1994. The relationship between energy expenditure during incubation and clutch size in the Pied Flycatcher Ficedula hypoleuca. Journal of Avian Biology 25:125-130.

Murdoch, W. W. 1994. Population regulation in theory and practice-the Robert H. MacArthur Award lecture. Ecology 75:271-287.

Newton, I. 1998. Population limitation in birds. Academic Press, London, UK

Nicholson, A. J. 1933. The balance of animal populations. Journal of Animal Ecology 2:132-178.

Nur, N. 1986. Is clutch size variation in the Blue Tit Parus caeruleus adaptive? An experimental study. Journal of Animal Ecology 55:983-999.

Oppliger, A., P. Christe, and H. Richner. 1996. Clutch size and malaria resistance. Nature (London) 381:565.

Perrins, C. M. 1966. The effect of beech crops on Great Tit populations and movements. British Birds 59:419-432.

Perrins, C. M. 1970. The timing of birds' breeding seasons. Ibis 112:242-255.

Perrins, C. M., and R. H. McCleery. 1994. Competition and egg-weight in the Great Tit Parus major. Ibis 136:454-456.

Perrins, C. M., and D. Moss. 1975. Reproductive rates in the Great Tit. Journal of Animal Ecology 44:695-706.

Petersen, K. L., and L. B. Best. 1987. Territory dynamics in a Sage Sparrow population: are shifts in site use adaptive? Behavioral Ecology and Sociobiology 21:351-358.

Pettifor, R. A. 1993a. Brood-manipulation experiments. 1. The number of offspring surviving per nest in Blue Tits Parus caeruleus. Journal of Animal Ecology 62:131-144.

Pettifor, R. A. 1993b. Brood-manipulation experiments. 2. A cost of reproduction in Blue Tits Parus caeruleus. Journal of Animal Ecology 62:145-159.

Pettifor, R. A., C. M. Perrins, and R. H. McCleery. 1988. Individual optimization of clutch size in Great Tits. Nature (London) 336:160-162.

Royal Statistical Society. 1992. GLIM 4. Royal Statistical Society, London, UK.

Sinclair, A. R. E. 1989. Population regulation in animals. Pages 197-241 in J. M. Cherrett, editor. Ecological concepts. Blackwell Scientific, Oxford, UK

Smith, S. G., J. R. Skalski, W. Schlechte, A. Hoffmann, and V. Vassen. 1994. SURPH. 1 Manual of statistical surviva analysis for fish and wildlife tagging studies. Bonneville Power Administration Public Information Center, Portland, Oregon, USA.

Stearns, S. C. 1992. The evolution of life histories. Oxford University Press, Oxford, UK

Stearns, S. C., and J. Koella. 1986. The evolution of phenotypic plasticity in life history traits: predictions of re- action norms for age and size at maturity. Evolution 40: 893-913.

Sutherland, W. J. 1996a. Predicting the consequences of habitat loss for migrating populations. Proceedings of the Royal Society of London, Series B 263:133-138.

Sutherland, W. J. 1996b. From individual behaviour to population dynamics. Oxford University Press, Oxford, UK.

Tinbergen, J. M. 1987. Costs of reproduction in the Great Tit: intraseasonal costs associated with brood size. Ardea 75: $111-122$.

Tinbergen, J. M., and M. C. Boerlijst. 1990. Nestling weight and survival in individual Great Tits Parus major. Journal of Animal Ecology 59:1113-1127.

Tinbergen, J. M., and C. Both. 1999. Is clutch size individually optimized? Behavioral Ecology, 10:504-509.

Tinbergen, J. M., and S. Daan. 1990. Family planning in the Great Tit Parus major: optimal clutch size as integration of parent and offspring fitness. Behaviour 114:161-190.

van Balen, J. H. 1973. A comparative study of the breeding ecology of the Great Tit Parus major in different habitats. Ardea 61:1-93.

van Noordwijk, A. J., and G. de Jong. 1986. Acquisition and allocation of resources: their influence on variation in life history tactics. American Naturalist 128:137-142.

van Noordwijk, A. J., R. H. McCleery, and C. M. Perrins 1995. Selection for timing of Great Tit breeding in relation to caterpillar growth and temperature. Journal of Animal Ecology 64:451-458.

van Noordwijk, A. J., and C. B. Müller. 1994. On adaptive plasticity in reproductive traits, illustrated with laydate in the Great Tit and colony inception in a bumble bee. Pages 180-194 in P. J. Jarman and A. Rossiter, editors. Animal societies; individuals, interactions and organisation. Kyoto University Press, Kyoto, Japan.

Varley, G. C., and G. R. Gradwell. 1960. Key factors in population studies. Journal of Animal Ecology 29:399-401.

Verboven, N. 1998. Multiple breeding in a seasonal environment. Dissertation. University of Utrecht, Utrecht, The Netherlands.

Verboven, N., and M. E. Visser. 1998. Seasonal variation in local recruitment of Great Tits: the importance of being early. Oikos 81:511-524.

Verhulst, S. 1992. Effects of density, beech crop and winter feeding on survival of juvenile Great Tits; an analysis of Kluyver's removal experiment. Ardea 80:285-292.

Verhulst, S. 1995. Reproductive decisions in Great Tits, an optimality approach. Dissertation. University of Groningen, Groningen, The Netherlands.

Verhulst, S., J. H. van Balen, and J. M. Tinbergen. 1995. Seasonal decline in reproductive success of the Great Tit: variation in time or quality? Ecology 76:2392-2403.

Visser, M. E., A. J. van Noordwijk, J. M. Tinbergen, and C. M. Lessells. 1998. Warmer springs lead to mistimed reproduction in Great Tits (Parus major). Proceedings of the Royal Society of London, Series B 265:1867-1870.

Visser, M. E., and N. Verboven. 1999. Long term fitness effects of laying date. Oikos 85:445-450.

\section{APPENDIX}

The functions of the optimality model for clutch size, along with parameter estimates, are available in ESA's Electronic Data Archive: Ecological Archives E081-030. 